\title{
AVALIAÇÃO DE DANOS MECÂNICOS CAUSADOS EM BANANA "NANICÃO" DURANTE AS ETAPAS DE BENEFICIAMENTO, TRANSPORTE E EMBALAGEM ${ }^{1}$
}

\author{
JULIANA SANCHES ${ }^{2}$, PAULO A. M. LEAL ${ }^{3}$, JOSÉ H. SARAVALI ${ }^{4}$, SILVIA ANTONIALI ${ }^{5}$
}

RESUMO: Este estudo teve como objetivo a avaliação de danos mecânicos ocorridos na banana "Nanicão" durante o processo de beneficiamento, transporte, embalagem e distribuição, identificando os prováveis pontos críticos. Avaliaram-se os danos mecânicos causados após o transporte, despistilagem e primeira despenca; limpeza e classificação; acondicionamento nas embalagens e transporte, e amadurecimento. As embalagens estudadas foram: embalagem de madeira torito (18 $\mathrm{kg}$ ), madeira tipo $1 / 2$ caixa $(13 \mathrm{~kg})$ e papelão $(18 \mathrm{~kg})$. Verificou-se que, na etapa de acondicionamento e transporte das frutas até o centro de distribuição, duplicaram os defeitos leves e os defeitos graves quintuplicaram, causando podridões após a climatização. A embalagem de papelão não suportou o empilhamento e apresentou deformações, que resultaram no amassamento das frutas que estavam nas embalagens inferiores e no aumento significativo dos defeitos graves. As frutas acondicionadas nas embalagens envolvidas pelo plástico bolha apresentaram menos danos graves quando comparadas às demais embalagens, sem o plástico.

PALAVRAS-CHAVE: Musa cavendishii, qualidade, injúrias.

\section{MECHANICAL DAMAGES CAUSED IN BANANA “NANICÃO" IN THE IMPROVEMENT PROCESS, PACKING AND TRANSPORT}

SUMMARY: This study had as objective the evaluation of mechanical damages occurred in banana "Nanicão" during the improvement process, packing and distribution, identifying the probable critical points. The mechanical damages caused by transport, first cleaning; cleanness and sorting; preservation in the packing, transport, and mature were evaluated. The studied packing had been: torito wooden packing $(18 \mathrm{~kg})$, wood type $1 / 2$ box, $(13 \mathrm{~kg})$ and cardboard $(18 \mathrm{~kg})$. The stage of preservation and transport of the fruits to the distribution center duplicated the light defects and quintupled the serious defects, causing rottenness after the acclimatization. The cardboard packing did not support the piling up and presented deformations, that resulted in the kneading the fruits of the inferior packing, causing a significant increase of the serious defects. The fruits conditioned in the involved packing of plastic bubble had presented an inferior number of serious damages when compared with the others packing, without the plastic.

KEYWORDS: Musa cavendishii, quality, injuries.

\footnotetext{
${ }^{1}$ Parte da dissertação do primeiro autor apresentada à FEAGRI para a obtenção do título de Mestre em Engenharia Agrícola. Projeto financiado pela FAPESP

${ }^{2}$ Engenheira Agrônoma, Mestre em Tecnologia Pós-Colheita, Faculdade de Engenharia Agrícola, UNICAMP, Caixa Postal 6011, 13083-970, Campinas - SP, Fone: (0XX19) 3788.1037, Doutoranda em Produção Vegetal, FCAV/UNESP, Jaboticabal, e-mail: jsanches@fcav.unesp.br

${ }^{3}$ Engenheiro Agrícola, Professor Associado, Doutor, CAC-TPC, FEAGRI/UNICAMP, Campinas - SP, e-mail: pamleal@agr.unicamp.br

${ }_{5}^{4}$ Bolsista de Iniciação Científica CNPq, FEAGRI/UNICAMP, Campinas - SP.

${ }^{5}$ Engenheira Agrônoma, Doutoranda em Tecnologia Pós-Colheita, FEAGRI/UNICAMP, Campinas - SP.

Recebido pelo Conselho Editorial em: 9-5-2002

Aprovado pelo Conselho Editorial em: 19-11-2003
} 


\section{INTRODUÇÃO}

Segundo BORDIN (1998), desde o instante em que é colhido até o momento de ser preparado ou consumido, o produto hortícola é submetido a uma série de efeitos essencialmente mecânicos que, dependendo da sensibilidade do produto, poderá causar danos que comprometerão a qualidade final do mesmo.

Do total de bananas colhidas, somente cerca de $40 \%$ a $50 \%$ chegam efetivamente às mãos dos consumidores. Segundo TAGLIARI et al. (1994), isso ocorre devido às perdas causadas por danos ocorridos nas seguintes fases: do plantio até a colheita (devido à falta de planejamento do manejo da lavoura), no momento da colheita, no amontoamento dos cachos, nas embalagens de madeira, nos transportes interno e externo e no manuseio das frutas nas feiras e supermercados.

Os danos mecânicos levam ao escurecimento da casca e polpa, causam má aparência e favorecem a entrada de fungos causadores de podridões. Tais alterações resultam na queda da qualidade e do preço do produto, causando sérios problemas na comercialização da banana (THOMPSON \& BURDEN, 1996). Além de prejudicarem a aparência e a qualidade, os danos mecânicos levam ao amadurecimento precoce da banana, ocasionado pelo aumento na síntese de etileno. Segundo LICHTEMBERG (1999), os danos mecânicos ocorridos na colheita prejudicam a aparência da fruta e provocam perdas por cortes, rachaduras, esmagamento e posterior podridão das frutas.

Nas etapas de transporte manual dos cachos, embarque nos veículos transportadores e traslado dos cachos até a central de embalagem, ocorre a maioria das injúrias mecânicas produzidas nos frutos (MITCHELL, 1992 e SANTOS, 1998).

Durante o beneficiamento, as frutas também são submetidas a danos mecânicos cujos efeitos irão manifestar-se principalmente após a maturação. Porém, é no momento da embalagem que a fruta sofre os maiores danos, devido à utilização de embalagens inadequadas e, principalmente, em razão do excesso de carga nelas acondicionada (LICHTEMBERG, 1999). Uma caixa "torito" que tem capacidade para 18 a $20 \mathrm{~kg}$ de fruta, recebe em média $25 \mathrm{~kg}$ de banana, que além de ser prensada, ultrapassa a altura da embalagem. As conseqüências desse procedimento são frutas rachadas, raspadas nas bordas das embalagens e amassadas.

O transporte das frutas até os centros distribuidores também causa severos danos às frutas, principalmente quando se utilizam rodovias em péssimo estado de conservação.

Quando comercializadas no atacado e no varejo, as frutas continuam sendo danificadas pelo manuseio inadequado das embalagens nas etapas de carga e descarga e, ainda, no momento de exposição e comercialização do produto.

Devido à necessidade de melhoria do produto agrícola brasileiro, o Conselho Regional de Desenvolvimento Rural, juntamente com as Câmaras Setoriais de frutas e hortaliças lançaram o "Programa Paulista para a Melhoria dos Padrões Comerciais e Embalagens de Hortigranjeiros", elaborado pelo Centro de Qualidade em Horticultura da Companhia de Entrepostos e Armazéns Gerais de São Paulo (CEAGESP), hoje, um programa nacional (Programa Brasileiro para a Melhoria dos Padrões Comerciais e Embalagens de Hortigranjeiros - PBMPCEH) que tem por objetivo aumentar a competitividade dos agronegócios hortifrutícolas, por meio de classificação dos produtos, melhoria dos padrões de qualidade e embalagens, bem como das formas práticas de comercialização dessas mercadorias. Dentre os produtos considerados prioritários para os estudos, encontra-se a banana (CEAGESP, 1998).

O PBMPCEH estabeleceu a classificação quanto a defeitos em Tipo ou Categoria relacionado com a qualidade e medido pela quantidade de defeitos presentes no lote. Os defeitos podem ser leves, 
graves e variáveis. Defeito leve é aquele que deprecia o produto, mas não impede seu consumo, como as manchas e deformações. Defeito grave é aquele que impede o consumo, como as frutas imaturas, ou aquelas que têm um alto potencial de prejudicar os outros frutos da mesma embalagem, como as podridões ou danos profundos. Defeitos variáveis são aqueles que, dependendo da extensão, podem ser graves ou leves. O PBMPCEH também estabeleceu um critério para a classificação desses defeitos quanto ao tamanho da lesão, em $\mathrm{cm}^{2}$, para o enquadramento da fruta em defeitos graves ou leves, bem como a porcentagem permitida desses danos para a classificação da fruta, por lote.

Nesse contexto, o presente estudo teve como objetivo avaliar os danos mecânicos que ocorrem na banana "Nanicão" durante os processos de beneficiamento, transporte, embalagem e distribuição, identificando os prováveis pontos críticos e as embalagens que favorecem o maior número de danos.

\section{MATERIAL E MÉTODOS} Ribeira.

Utilizou-se da banana "Nanicão", proveniente do município de Registro - SP, região do Vale do

Para a avaliação dos danos mecânicos, foram utilizados seis cachos, num total de 995 dedos, sendo 116 pencas e/ou buquês e para as testemunhas, quatro cachos de banana, de forma aleatória, num total de 766 dedos. Para a quantificação dos danos, foram contadas as manchas obtidas em cada etapa percorrida pelas frutas e subtraindo-as à medida que passavam de uma etapa para outra, possibilitando a verificação do aumento de danos em cada etapa.

Os danos físicos ou mecânicos das bananas foram quantificados e qualificados segundo critérios de classificação do Programa Brasileiro para a Melhoria dos Padrões Comerciais e Embalagens de Hortigranjeiros (PBMPCEH), (CEAGESP, 1998), após as seguintes etapas de beneficiamento:

Após a colheita, despistilagem e primeira despenca: os cachos foram transportados até o galpão de beneficiamento em caminhão-"cegonha", pendurados verticalmente e distantes uns dos outros por barras de ferro e cordas. Esse procedimento foi adaptado pelos produtores da região do Vale do Ribeira, na tentativa de reduzir os danos causados pelo transporte do campo até o galpão de beneficiamento. No galpão, os cachos foram dispostos em trilhos com ganchos móveis e levados na vertical, sem o contato com o chão, até o setor em que foram retirados os restos florais. Os cachos analisados foram escolhidos aleatoriamente. Depois da despistilagem, foi realizada a primeira despenca dos cachos, e os dedos das pencas foram marcados um a um com caneta de retroprojetor próximo ao pedicelo. As pencas obtidas foram classificadas mediante qualificação e quantificação dos danos observados.

Após a limpeza, a lavagem e classificação das frutas: após a primeira despenca, as frutas foram mergulhadas em água para a retirada das impurezas e o calor de campo. Posteriromente, as frutas foram classificadas quanto a dedos defeituosos, observando-se o excesso de curvatura, os que não atingiram o comprimento exigido, bem como aqueles que estavam com danos mecânicos. Efetuouse outra despenca, obtendo-se pencas de até 12 dedos ou buquês de até 5 dedos, que foram mergulhados em um tanque com jatos de água na superfície e água com detergente neutro (1 L de detergente/3.000 L de água).

Após serem retiradas do tanque, as frutas foram pulverizadas com sulfato de alumínio $(1 \mathrm{~kg}$ de sulfato/50 L de água), com o produto "Ecolife" (vitaminas e ácidos orgânicos revigorantes e antiestresses para as plantas, com concentração de $100 \mathrm{~mL} / 50 \mathrm{~L}$ de água), com detergente neutro (50 mL de detergente $/ 50 \mathrm{~L}$ de água) e novamente avaliadas quanto aos danos mecânicos causados após esse processo. As frutas escolhidas para fazerem parte da testemunha passaram por todo o processo de limpeza e classificação, assim como as demais, mas tomou-se todo o cuidado possível para não causar dano a elas, passando penca e/ou buquê um a um nos tanques e pulverizados. 
Em seguida, as frutas foram acondicionadas em embalagens de madeira tipo "torito", com capacidade para $18 \mathrm{~kg}$ de banana, em embalagens de madeira tipo 1/2 caixa, com capacidade de $13 \mathrm{~kg}$ e em embalagens de papelão (capacidade para $18 \mathrm{~kg}$ de fruta). No acondicionamento das testemunhas, foram utilizadas caixas tipo "torito", com menos pencas que os acondicionamentos normais, tomandose o cuidado para evitar que as frutas sofressem danos devido ao excesso de carga nas embalagens, e acondicionados com proteção de plástico bolha $(3 \mathrm{~mm})$ ao redor das embalagens e em cada camada de sobreposição das frutas.

Após o acondicionamento nas embalagens e transporte até Campinas - SP: depois de acondicionadas nas embalagens, as frutas foram transportadas em caminhão baú térmico (temperatura de $25^{\circ} \mathrm{C} \pm 1$ ) até a câmara de climatização situada na CEASA de Campinas - SP. Os danos mecânicos causados após o acondicionamento nas embalagens e transporte foram novamente avaliados antes da entrada na câmara de climatização e novamente reacondicionados.

Após a maturação: as embalagens foram transportadas para o laboratório de Controle Ambiental da FEAGRI - UNICAMP, onde os danos foram novamente avaliados.

Utilizou-se do delineamento estatístico inteiramente casualizado (DIC) e avaliou-se a população total das frutas para cada embalagem, no total de nove embalagens ( 3 embalagens $/ 3$ repetições), bem como nove embalagens envolvidas por plástico bolha (testemunha).

\section{RESULTADOS E DISCUSSÃO}

Conforme demonstrado na Tabela 1, os defeitos graves aumentaram a cada etapa, e o transporte contribuiu para que o porcentual de frutas com defeitos graves atingisse $41,10 \%$. Como o limite máximo de frutas com defeitos graves é $20 \%$ (Categoria III), as frutas avaliadas não se encaixaram em nenhuma categoria. Observa-se, ainda, que até antes do acondicionamento nas embalagens, as frutas apresentavam 4,22\% de defeitos graves, enquadrando-se na Categoria I do PBMPCEH.

TABELA 1. Porcentagem das frutas com defeitos graves e leves identificadas em cada etapa.

\begin{tabular}{ccccc}
\hline Defeitos & $\begin{array}{c}\text { Após Colheita, } \\
\text { Despistilagem e } \\
\text { Primeira Despenca }\end{array}$ & $\begin{array}{c}\text { Após Lavagem e } \\
\text { Classificação }\end{array}$ & $\begin{array}{c}\text { Após } \\
\text { Acondicionamento } \\
\text { e Transporte }\end{array}$ & $\begin{array}{c}\text { Após } \\
\text { Amadurecimento }\end{array}$ \\
\hline Defeitos graves & & & & \\
\hline Amassados & 0,40 & 0,20 & 4,02 & 5,63 \\
Dano profundo & 0,20 & 0,20 & 0,40 & 0,80 \\
Queimado de Sol & 0,00 & 0,00 & 0,00 & 0,00 \\
Podridão & 0,00 & 0,00 & 0,00 & 0,00 \\
Lesão/mancha & 3,62 & 3,82 & 36,68 & 46,73 \\
Imaturo & 0,00 & 0,00 & 0,00 & 0,00 \\
\hline Total de defeitos & 4,22 & 4,22 & 41,10 & 53,16 \\
graves & 95,78 & 95,78 & 58,90 & 46,84 \\
\hline Defeitos leves & &
\end{tabular}

Durante a avaliação dos danos, observa-se que a totalidade das frutas apresentou lesões por tripes, resultando na desclassificação do produto, visto que o limite permitido para a Categoria III é de $20 \%$ desse defeito. A falta de tratos culturais adequados no processo de produção provocou um aumento expressivo da praga tripes, que foi observada por pintas na casca, provocada pelo inseto sugador e manchas entre os dedos, causados pelo inseto raspador, desclassificando as frutas automaticamente para a Categoria III do PBMPCEH. O produtor deverá, urgentemente, tomar medidas 
quanto aos tratos culturais na lavoura para a erradicação dessa praga e atingir, pelo menos, a classificação em Categoria II.

Na Tabela 2, apresentam-se os resultados de avaliação do produto, quanto à incidência de defeitos leves e graves ao longo de cada etapa. Os danos de cada etapa foram desconsiderados em relação à etapa posterior, mediante a subtração dos valores obtidos anteriormente.

Observa-se que, após a colheita, as frutas apresentaram, em média, 3,6 danos (23,7\%), que podem ter ocorrido no campo ou no transporte até o galpão de beneficiamento. Após o acondicionamento nas embalagens e transporte até o centro de distribuição, observou-se a duplicação de tais valores. O porcentual de defeitos graves inicial, de $8,3 \%$, resultou das etapas de campo ou transporte até o galpão de beneficiamento, sendo que, após o acondicionamento e transporte até o centro de distribuição, tais valores atingiram $50,0 \%$.

TABELA 2. Avaliação da incidência de defeitos graves e leves observados nas frutas em cada etapa.

\begin{tabular}{|c|c|c|c|c|c|c|c|c|}
\hline \multirow[t]{2}{*}{ Etapas } & \multicolumn{2}{|c|}{ Defeitos Leves } & \multicolumn{2}{|c|}{ Defeitos Graves } & \multicolumn{2}{|c|}{$\begin{array}{l}\text { Defeitos Leves } \\
\text { (testemunha) }\end{array}$} & \multicolumn{2}{|c|}{$\begin{array}{c}\text { Defeitos Graves } \\
\text { (testemunha) }\end{array}$} \\
\hline & Unidade & $\%$ & Unidade & $\%$ & Unidade & $\%$ & Unidade & $\%$ \\
\hline $\begin{array}{l}\text { Após colheita, } \\
\text { despistilagem e } \\
\text { primeira despenca }\end{array}$ & $3,6 \mathrm{Bb}$ & 23,7 & $0,1 \mathrm{Cb}$ & 8,3 & $5,4 \mathrm{Aa}$ & 79,4 & $0,0 \mathrm{Dc}$ & 0,0 \\
\hline $\begin{array}{l}\text { Após lavagem e } \\
\text { classificação } \\
\text { Anós }\end{array}$ & $3,2 \mathrm{Ac}$ & 21,1 & $0,0 \mathrm{Bc}$ & 0,0 & $0,0 \mathrm{Bd}$ & 0,0 & $0,0 \mathrm{Bc}$ & 0,0 \\
\hline $\begin{array}{l}\text { acondicionamento } \\
\text { e transporte }\end{array}$ & $6,4 \mathrm{Aa}$ & 42,1 & $0,6 \mathrm{Ba}$ & 50,0 & $0,5 \mathrm{Bc}$ & 7,4 & $0,3 \mathrm{Ca}$ & 75,0 \\
\hline $\begin{array}{c}\text { Após } \\
\text { amadurecimento }\end{array}$ & 2,0 Ad & 13,2 & $0,5 \mathrm{Cd}$ & 41,7 & $0,9 \mathrm{Bb}$ & 13,2 & $0,1 \mathrm{Db}$ & 25,0 \\
\hline Total & 15,2 & 100,0 & 1,2 & 100,0 & 6,8 & 100,0 & 0,40 & 100,0 \\
\hline
\end{tabular}

Conforme os resultados obtidos, pode-se observar que os pontos críticos de aumento de danos ocorrem até a chegada ao galpão de beneficiamento, danos esses trazidos do campo, após o acondicionamento das frutas nas embalagens e durante o transporte até o centro de distribuição. Isso pode ser explicado pela sobrecarga na embalagem e, conseqüentemente, o maceramento dos dedos entre eles e no contato com as embalagens e, ainda, pelas más condições das rodovias, que favorecem a alta vibração do produto entre a propriedade produtora e os centros de distribuição.

Conforme descrito anteriormente, as testemunhas foram envolvidas por plástico bolha para a minimização dos danos e, mesmo assim, após o transporte, os defeitos leves aumentaram 7,4\% e os graves $13,2 \%$. Observou-se, também, que, apesar de as frutas-testemunha terem sofrido danos, esses foram bem inferiores quando comparados às frutas acondicionadas nas demais embalagens. Fica, com isso, uma indicação para a aplicação futura dessa metodologia como forma de redução desses danos no processo de comercialização, não se esquecendo de que, também, se faz necessária a diminuição do peso de frutas por embalagem.

Na Tabela 3, apresenta-se o efeito das embalagens na incidência de defeitos leves e graves. Foram adicionadas as porcentagens de defeitos leves e graves durante o transporte e após o amadurecimento, calculando-se as respectivas porcentagens de cada embalagem. 
TABELA 3. Incidência de defeitos leves e graves observados no produto acondicionado nas diferentes embalagens.

\begin{tabular}{ccccc}
\hline Tipo de Embalagem & Defeitos Leves & \% Defeitos Leves & Defeitos Graves & \% Defeitos Graves \\
\hline Papelão & $8,4 \mathrm{Aa}$ & 18,4 & $0,7 \mathrm{Ba}$ & 58,3 \\
$1 / 2$ caixa & $8,7 \mathrm{Aa}$ & 19,1 & $0,2 \mathrm{Ba}$ & 16,7 \\
Torito & $8,1 \mathrm{Aa}$ & 17,8 & $0,2 \mathrm{Ba}$ & 16,7 \\
Total* & 25,2 & $55,3^{*}$ & 1,1 & $91,7^{*}$ \\
\hline
\end{tabular}

* Danos observados após acondicionamento, transporte e amadurecimento. Médias seguidas por uma mesma letra, maiúscula na linha e minúscula na coluna, não diferem significativamente entre si, pelo teste de Tukey $(\mathrm{P}<0,05)$

Na Tabela 3, observa-se que o produto acondicionado na embalagem de papelão apresentou $58,3 \%$ de defeitos graves, enquanto, nas embalagens $1 / 2$ caixa e torito, esse índice foi de $16,7 \%$. Por meio desse resultado, verificou-se que a embalagem de papelão não se mostrou apropriada para $o$ acondicionamento das frutas. Devido à baixa resistência ao empilhamento, as caixas sofreram deformações causadas pelo peso do produto, resultando no amassamento das frutas e favorecendo um aumento significativo dos defeitos graves. Com isso, necessita-se de estudos para a elaboração de uma embalagem de papelão mais apropriada, que apresente reforços laterais capazes de suportar o empilhamento e, conseqüentemente, a paletização.

Deve-se ressaltar que, na avaliação dos defeitos graves e leves, em cada etapa do beneficiamento, tomou-se o máximo de cuidado para que o manuseio adotado na metodologia aplicada não provocasse danos, mas, mesmo assim, esse manuseio contribuiu muito para o aumento desses danos, principalmente após o transporte das frutas.

O Programa Brasileiro para a Melhoria dos Padrões Comerciais e Embalagens de Hortigranjeiros estabelece que, para o enquadramento da banana em categorias de venda, é necessário avaliar todo o lote; isso sempre causará aumento de danos ocasionados com o aumento no manuseio da fruta para a avaliação em questão, comprovando que o aumento no manuseio proporciona perda de qualidade.

Quanto às avaliações de defeitos, para quantificar em graves e leves, foi encontrada uma dificuldade no critério adotado para o tamanho de lesão grave e leve. Além de trabalhoso, demanda considerável tempo para a avaliação das frutas de uma única embalagem. Portanto, faz-se necessária uma reavaliação desse critério, sem perder a confiabilidade. Apesar da dificuldade na avaliação, é muito importante a utilização de uma metodologia uniforme de classificação dos produtos hortifrutícolas brasileiros, de modo a torná-los competitivos e, conseqüentemente, provocar um aumento na qualidade dos produtos vendidos internamente, em especial a banana, que poderia vir a ser exportada.

\section{CONCLUSÕES}

Os métodos de manuseio utilizados pela propriedade, o acondicionamento das frutas nas embalagens e o transporte até o centro de distribuição favoreceram o aumento de danos mecânicos nas bananas, duplicando os defeitos leves e quintuplicando os defeitos graves, causando podridões após a climatização, principalmente quanto ao aparecimento de lesões ou manchas graves.

Os danos mecânicos podem acontecer em qualquer etapa pós-colheita, seja manual, seja mecanizado. A embalagem de papelão não se mostrou adequada ao acondicionamento da banana por resultar em um aumento significativo dos defeitos graves. Para as demais embalagens testadas, o envolvimento dos frutos pelo plástico bolha permitiu a redução dos danos graves, quando comparado ao produto não protegido. 
Sendo assim, os programas que minimizem a incidência de danos devem ser incentivados, com o objetivo de motivar os produtores no manuseio adequado das frutas, na identificação dos pontos críticos e na adoção de técnicas de melhoria dos processos de produção e comercialização.

\section{AGRADECIMENTOS}

Os autores agradecem à FEAGRI e à FAPESP (01/00275-2), pelo auxílio à pesquisa, e à CAPES, CNPq e PIBIC-CNPq, pelas bolsas concedidas.

\section{REFERÊNCIAS BIBLIOGRÁFICAS}

BORDIN, M.R. Embalagem para frutas e hortaliças In: Tecnologia de resfriamento de frutas e hortaliças. Campinas: Faculdade de Engenharia Agrícola, 1998. p.19-27.

LICHTEMBERG, L.A. Colheita e pós-colheita da banana. Informe Agropecuário, Belo Horizonte, v.20, n.196, p.73-90, jan./fev.1999.

MITCHELL, F.G. The need for cooling. In: KADER, A.A. (Ed.) Postharvest technology of horticultural crops. 2. ed. California: Division of Agriculture and Natural Resources, University of California, 1992. p.53-6. (Publ. n. 3311)

COMPANHIA DE ENTREPOSTOS E ARMAZÉNS GERAIS DE SÃO PAULO - CEAGESP. Programa brasileiro para a melhoria dos padrões comerciais e embalagens de hortigranjeiros. Classificação da banana. São Paulo: Centro de Qualidade em Horticultura, 1998. 5 p.

SANTOS, J.H. Processamento pós-colheita de banana (Musa cavendishii cultivar Nanicão): injúrias mecânicas do fruto devido ao transporte manual. 1998. 98 f. Dissertação (Mestrado em Máquinas Agrícolas) - Universidade Estadual de Campinas, Campinas, 1998.

TAGLIARI, P.S.; FRANCO, H.M. Manejo pós-colheita da banana. Agropecuário Catarinense, Florianópolis, v.7, n.2, p.25-30, jun.1994.

THOMPSON, A.K.; BURDEN, O.J. Harvesting and fruit care. In: GOWEN, S. (Ed.) Bananas and plantains. London: Chapman e Hall., 1996. 256 p. 
O arquivo disponível sofreu correções conforme ERRATA publicada no Volume 24 Número 3 da revista. 